\title{
Daily Fluctuations in Motivation
}

\section{A Longitudinal Diary Study Over an Entire Semester at University}

\author{
Henrik Bellhäuser ${ }^{1} \oplus$, Björn Mattes², and Patrick Liborius ${ }^{3}$ \\ 'Johannes Gutenberg-University Mainz \\ ${ }^{2}$ Technical University of Darmstadt \\ ${ }^{3}$ University Liechtenstein
}

\begin{abstract}
Intrinsic and extrinsic motivation are related to learning success and academic achievement of university students. Process models of self-regulated learning (SRL) suggest that daily academic motivation is affected by study satisfaction on the previous day. In this study, we conducted a secondary analysis of the data by Liborius et al. (2019), in which the study behavior of a total of 105 students was surveyed daily over 154 days (including both the lecture period and non-lecture period). We tested a mediation model, assuming that SRL components (planning, self-efficacy, time investment, concentration, effort, and procrastination) increase intrinsic motivation and decrease extrinsic motivation on the next day through their effects on study satisfaction. The results showed the proposed mediation effects for all predictors except for planning. The study underlined the importance of investigating SRL and motivation on a daily level. Further, we showed that effects can vary between the lecture period and non-lecture period.
\end{abstract}

Keywords: diary study, students' daily motivation, time-series analyses, self-regulated learning

Tägliche Fluktuationen der Motivation - Eine Tagebuchstudie über ein ganzes Semester an der Universität

Zusammenfassung: Intrinsische und extrinsische Motivation stehen im Zusammenhang mit dem Lernerfolg und der akademischen Leistung von Universitätsstudenten. Prozessmodelle des selbstregulierten Lernens (SRL) legen nahe, dass die tägliche akademische Motivation von der Studienzufriedenheit am Vortag beeinflusst wird. In dieser Studie führen wir eine Sekundäranalyse der Daten von Liborius et al. (2019) durch, in der das Studienverhalten von insgesamt N = 105 Studierenden täglich über 154 Tage erhoben wurde (inklusive Vorlesungszeit und vorlesungsfreie Zeit). Wir testen ein Mediationsmodell, in dem wir annehmen, dass SRL-Komponenten (Planung, Selbstwirksamkeit, Zeitinvestition, Konzentration, Anstrengung und Prokrastination) durch ihre Effekte auf die Studienzufriedenheit die intrinsische Motivation erhöhen und die extrinsische Motivation am nächsten Tag senken. Die Ergebnisse zeigen die vorgeschlagenen Mediationseffekte für alle Prädiktoren außer für die Planung. Die Studie unterstreicht die Bedeutung der Untersuchung von SRL und Motivation auf täglicher Ebene. Weiterhin zeigen wir, dass die Effekte zwischen Vorlesungszeit und vorlesungsfreier Zeit variieren können.

Schlüsselwörter: Tagebuchstudie; tägliche Motivation von Studierenden; Zeitreihenanalysen; Selbstreguliertes Lernen; Mehrebenen-Mediationsanalyse

Academic motivation has consistently been shown to be an influential factor for students' learning and performance both in school and in university (Eccles \& Wigfield, 2002; Richardson et al., 2012; Steinmayr \& Spinath, 2007), and plays a decisive role in the context of self-regulated learning (SRL). While there is an abundance of different theoretical models of motivation (Sansone \& Harackiewicz, 2000), many theories differentiate between intrinsic motivation (IM) and extrinsic motivation (EM): "intrinsic motivation [...] refers to doing something because it is inherently interesting or enjoyable, and extrinsic motivation [...] refers to doing something because it leads to a separable outcome" (Ryan \& Deci, 2000, p. 55). This distinction is particularly important as these two constructs relate differently to learning and performance. In their meta-analysis, Richardson et al. (2012) found IM to be an important predictor of performance, while EM did not seem to be systematically associated with performance - thereby making a case for the distinction of IM and EM in the context of SRL at universities. Taylor et al. (2014) for example, showed that over a period of 1 year, IM was the only motivation type that was positively associated with academic achievement (controlling for baseline achievement).

While there is a plenitude of work on academic motivation as a predictor variable, studies on antecedents of academic motivation are remarkably rare. In addition, a majority of studies have investigated academic motivati- 


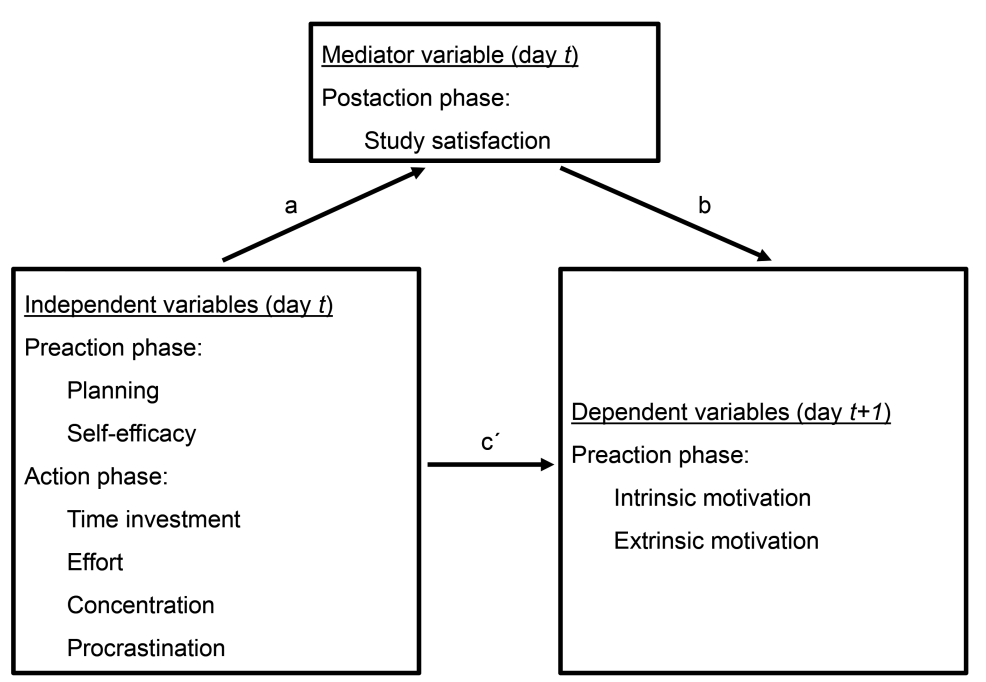

Figure 1. Conceptual model. on from an interpersonal perspective, neglecting intrapersonal dynamics of academic motivation, that is, motivational fluctuations over longer periods (Mouratidis et al., 2017). Such fluctuations can occur on several time levels. On the macro level, spanning over several months or even years, one example would be the continuous decline in IM of students during their school career (Scherrer \& Preckel, 2019). The micro level investigates short time frames of hours or even only minutes, such as motivational fluctuations from one chess game to the next (Abuhamdeh \& Csikszentmihalyi, 2009). A middle ground between these two levels, the meso level, is the fluctuation of academic motivation from day to day, which has not been investigated as intensively (Ketonen et al., 2018; Mouratidis et al., 2017; Murayama et al., 2017; Patall et al., 2018).

Daily fluctuations in academic motivation can be studied within the framework of the process model of SRL (Schmitz \& Wiese, 2006), which divides the learning process into three iterative phases: the preaction phase (in which goal-setting and planning take place), the action phase (in which the actual learning happens), and the postaction phase (in which the outcomes are evaluated). These phases are conceptualized as being cyclical, with one phase affecting the next one. Specifically, the model suggests that one learning cycle influences the next in the sense that the outcome from the postaction phase of the first learning cycle (i.e., study satisfaction) has an effect on the preaction phase of the next learning cycle (i.e., next day's IM and EM). The process model thereby emphasizes the importance of trajectories, within-person variability, and intrapersonal dynamics (Murayama et al., 2017; Schmitz, 2006;).

Just like motivation, SRL takes place on different time levels: On the macro level, one learning cycle could, for example, be the process of studying for final exams (e.g, Theobald et al., 2018). On the micro level, it can be as short as a single task, like calculating a complex math problem (e.g., Perels et al., 2005). For the present study we are interested in the meso level, that is, learning processes from one day to the next.

Consequently, the goal of the present study was to predict daily fluctuations in IM and EM on the basis of learning-related variables from the previous day. We did so by means of a secondary analysis of extensive longitudinal diary data by Liborius et al. (2019), covering one entire lecture period at university and the subsequent non-lecture period ( 5 months in total). Thereby, we tested one central assumption of the process model of SRL (Schmitz \& Wiese, 2006): That the postaction phase serves as a mediator between the prior preaction and action phase and the subsequent preaction phase. We tested this mediation hypothesis with a parsimonious selection of components from all three phases of the process model (see Figure 1). As predictor variables, we used planning (Pintrich, 2000) and self-efficacy (Honicke \& Broadbent, 2016) from the preaction phase as well as time investment (Rosário et al., 2013), effort (Hiemstra \& Van Yperen, 2015), concentration (Hidi \& Renninger, 2019), and procrastination (Klassen et al., 2008) from the action phase. Study satisfaction (Liborius et al., 2019) from the postaction phase served as the mediator variable. As dependent variables, we used IM and EM in the morning of the following day. In the next section, we explain in more detail the rationale behind the selection of variables. 


\section{Theory and Hypotheses Development}

In this section, we derive directed hypotheses for associations between different SRL components (planning, self-efficacy, time investment, effort, concentration, and procrastination) in study satisfaction and its subsequent effect on the next day's IM and EM. In other words, we argue that daily study satisfaction plays a mediating role between SRL components on one day and intrinsic and extrinsic motivational states on the following day.

\section{Self-Regulated Learning and Daily Study Satisfaction}

According to the process model of SRL (Schmitz \& Wiese, 2006),), self-regulated learning takes place in three iterative phases. In the preaction phase, students decide on their goals and create a plan on how to achieve their goals. Planning, as a metacognitive strategy, involves identifying and organizing the individual subtasks that are necessary for, as well as empirically related to, goal achievement (e.g., task performance: Dermitzaki et al., 2009). Additionally, self-efficacy is needed to believe that they are capable of achieving their goals and is also empirically related to achievement (Caprara et al., 2008).

In the subsequent action phase, learners invest time for learning (quantity activity) and they use learning strategies (i.e., concentration and effort). Time investment is a necessary but not sufficient prerequisite for successful learning. While investing time, students also need to make an effort, keep up with their concentration during their study day, and try to avoid tendencies to procrastinate. All of these variables have been found to be empirically related to goal achievement (for concentration, see Pekrun et al., 2010; for effort, see Trautwein, 2007; for procrastination, see Wäschle et al., 2014) or similar variables that are a deciding factor for students end-of-the-day evaluation of their study day (i.e., daily study satisfaction).

In the postaction phase, learners evaluate their learning process and reflect on how they want to proceed. When all SRL components work well together, the learning process should be successful and should thereby increase study satisfaction. Liborius et al. (2019) empirically demonstrated that SRL components such as planning, self-efficacy, time investment, effort, concentration, and procrastination have an effect on daily study satisfaction. In conclusion, we derived the following hypotheses (see Figure 1, Path a):

H1: Planning (H1a), self-efficacy (H1b), time investment (H1c), effort (H1d), and concentration (H1e) on one day would be positively related to study satisfaction on the same day, whereas procrastination (H1f) would be negatively related to study satisfaction.

\section{Daily Study Satisfaction and Academic Motivation on the Following Day}

Study satisfaction marks the end point of one cycle of the process model of SRL and is assumed to influence the starting point of the next cycle - the next day's academic motivation (i.e., IM and EM). One of the dominant theories in research on motivation is the self-determination theory by Deci and Ryan (2012), in which they proposed that prerequisites for IM are that the person feels competent and autonomous (see also Radel et al., 2014). EM on the other hand arises from a certain pressure to do something, whether to get some future value or avoid some future disvalue (Locke \& Schattke, 2019).

Daily study satisfaction is a student's (affective) evaluation regarding his/her study day and as such a selfevaluation of his/her study performance (Schmitz \& Wiese, 2006). Reeve (1989) demonstrated that perceived performance predicts enjoyment and as such contributes to intrinsic motivation. In addition, Isen and Reeve (2005) showed a positive relation between positive affect and motivation. Further empirical evidence that study satisfaction may affect intrinsic motivation on the next day (meso level) comes from diary studies by Ketonen et al. (2018) as well as Harper et al. (2020), who found a positive relation between positive emotions and intrinsic motivation.

In the case of low study satisfaction, students negatively evaluate their daily study performance, which is most probably accompanied by negative emotions. Extrinsic motivation has been found to be positively related to negative emotions on the meso level in a diary study by Perunovic et al. (2011). Thus, daily study satisfaction should be negatively related to extrinsic motivation the next day.

Taken together, we expected higher study satisfaction to increase IM because after a successful study day, students should experience a feeling of competency, which is a central aspect of IM. Likewise, we expected higher study satisfaction to decrease EM because after a successful studying day, students should have fewer tasks to do on their list and should therefore feel less pressure to study. In conclusion, we derived the following hypotheses (see Figure 1, Path b): 
H2: Daily study satisfaction on one day would be positively related to intrinsic motivation (H2a) and negatively related to extrinsic motivation the following day (H2b).

\section{The Mediating Effect of Study Satisfaction in the Self-Regulated Learning Cycle}

According to the aforementioned argumentation regarding the relationship between SRL and study satisfaction as well as the relationship between study satisfaction and academic motivation, we proposed that the SRL components on one day influence IM and EM on the following day, mediated by study satisfaction. This proposed mediation process is consistent with the process view that SRL is cyclical in nature (Schmitz \& Wiese, 2006; Zimmerman, 2000). From that view, the postaction phase on one day (i.e., study satisfaction) affects the preaction phase on the following day (i.e., motivation). We therefore argue that students' daily study satisfaction acts as a mediator between the SRL components on one day and students' IM and EM on the following day. In conclusion, we derived the following hypotheses (see Figure 1, Path $\left.a^{*} b\right)$ :

H3: Planning (H3a), self-efficacy (H3b), time investment $(\mathrm{H} 3 \mathrm{c})$, effort $(\mathrm{H} 3 \mathrm{~d})$, and concentration $(\mathrm{H} 3 \mathrm{e})$ would be positively related to, whereas procrastination ( $\mathrm{H} 3 \mathrm{f})$ would be negatively related to, intrinsic motivation on the following day, mediated by study satisfaction.

H4: Planning (H4a), self-efficacy (H4b), time investment $(\mathrm{H} 4 \mathrm{c})$, effort $(\mathrm{H} 4 \mathrm{~d})$, and concentration $(\mathrm{H} 4 \mathrm{e})$ are negatively related to, while procrastination $(\mathrm{H} 4 \mathrm{f})$ is positively related to, extrinsic motivation on the following day, mediated by study satisfaction.

In addition, whether or not the individual SRL components also have an effect on IM and EM that is not mediated by study satisfaction (see Figure 1, Path $c^{\prime}$ ) was an exploratory question that we aimed to answer.

\section{Method}

\section{Participants}

In this paper, we present a secondary analysis of data collected by Liborius et al. (2019). Recruitment took place in various departments of a technical university in Germany within the first 2 weeks of the lecture period. Students from both bachelor and master level could participate. While 554 students responded to the initial questionnaire, 232 actually took part in the daily questionnaires. After exclusion of participants who did not achieve the quota of
$80 \%$ of completed daily questionnaires over the whole semester, the final sample consisted of 105 students.

The average age in the final sample was 22.32 years ( $S D$ $=2.81$ ). Participants had been attending university on average for 4.39 semesters $(S D=2.68)$, with $62.86 \%$ being undergraduates. The sample included a large number of different majors that can be clustered into engineering studies $(n=70)$, natural sciences $(n=16)$, humanities $(n=10)$, and teacher education $(n=9)$. Participants were predominantly male $(n=66)$, which is usual for technical universities in Germany.

\section{Dropout Analyses}

We investigated whether the final sample differed systematically from students who dropped out of the study. In the initial questionnaire, we found no significant differences for gender, $t(223.19)=-0.59, p=.56$; semester, $t(202.90)=-0.75, p=.45$; trait IM, $t(169.09)=1.65, p=$ .10 ; trait EM, $t(181.18)=-0.39, p=.70$; general study satisfaction, $t(223.25)=1.35, p=.18$; and general study load, $t(209.47)=-0.99, p=32$. Dropouts, however, were significantly younger $(M=22.37)$ than students who completed the study $(M=23.33), t(202.52)=-2.78, p=.006$.

\section{Procedure}

The initial survey took place during the first 2 weeks of the lecture period, which was also the time frame for recruiting participants. In this online survey, participants reported their age, current term, academic major, overall study satisfaction, overall study load, and trait IM and EM.

After completing the initial survey, participants started the daily diary survey at the beginning of the third week of the lecture period. The diary phase of our study lasted until the end of the term 5 months later, for a total of 22 weeks (12 weeks of lecture period and 10 weeks of nonlecture period). Participants received $€ 100$ as an incentive if they reached an $80 \%$ quota in the diary phase.

The diary entries were made online via personal computer, laptop, smartphone, or smartphone app, using a personal, password-protected account. Participants were prompted regularly to fill in the diaries, which consisted of two parts: a morning diary (to be filled in between 5 a.m. to 3 p.m., assessing IM and EM, planning, and self-efficacy) and an evening diary (to be filled in between 7 p.m. to 3 a.m., assessing effort, concentration, procrastination, and satisfaction). Time investment for study-related tasks could be entered at any given time. Without objective data, we estimate that participants needed 3-4 min for each of the two parts of the diary. 


\section{Instruments}

\section{Initial Survey}

In order to control for individual differences between participants, we applied an initial self-report survey measuring two covariates that are known to have an impact on IM and EM without defining directed hypotheses for these covariates: study load (LePine et al., 2004) and study satisfaction (Nowell, 2017). Additionally, trait IM and trait EM were measured as further covariates.

Study load. A modified version of the 5-item scale from Baumert et al. (2009) was used to assess students' overall study load (e.g., "I often feel exhausted in university"). Participants rated each item on a 6-point Likert-scale from 1 (strongly disagree) to 6 (strongly agree). Internal consistency was calculated to be Cronbach's $\alpha=.81$.

Study satisfaction. We used an adapted version of the 5item scale from Baumert et al. (2009) to assess students' overall study satisfaction (e.g., "For me there is no better field of study"). Each item was rated on a 6-point Likertscale ranging from 1 (strongly disagree) to 6 (strongly agree). Internal consistency was $\alpha=.84$.

Intrinsic and extrinsic motivation. Trait IM and EM were assessed using an adapted version of the SRQ-A (Ryan \& Connell, 1989). Each motivational scale consisted of four items. IM (e.g., "I study because I enjoy dealing with my field of study") had an internal consistency of Cronbach's $\alpha=.86$; internal consistency of the EM scale (e.g., "I'm studying because I'd feel bad if I didn't") was $\alpha=.74$.

Demographic data. Finally, the initial survey included a demographic with age, major, and number of terms at university.

\section{Daily Learning Diary}

Daily measurements of self-regulated learning and motivation were conducted using one item per construct with a 6-point Likert-scale ranging from 1 (strongly disagree) to 6 (strongly agree). All items were taken from Liborius et al. (2019). Both dependent variables were assessed in the morning diary: one item for IM ("Today I am looking forward to my studies and to dealing with its contents") and one item for EM ("Today I am driven to study mainly by the pressure I have"). As predictor variables, we assessed five constructs from the process model of SRL (Schmitz \& Wiese, 2006) using 1-item scales for each construct. Two constructs were assessed in the morning diary: planning ("I have a specific plan, according to which I will perform today's study-related tasks") and self-efficacy ("I know how to proceed today to make it a successful study day"). Three more constructs were assessed in the evening diary: effort ("Today, I made an effort"), concentration ("During my current study-related activities - attendance and self-study - I was very concentrated”), and procrasti- nation ("Today, I have postponed unpleasant things"). Further, we assessed daily study satisfaction ("I am very satisfied with what I have achieved today [study relevant]") as the mediator variable.

One more predictor variable - time investment - differed from the other predictor variables concerning its mode of assessment: Students reported their time investment in the diary by entering separately how much time they invested in attending lectures and in studying independently (in minutes). Both numbers were then added as the overall time investment.

Since 1-item scales prohibit the calculation of traditional measures of reliability (i.e., internal consistency), we followed the recommendations by Watson (1988) as well as Schmitz and Skinner (1993) employing stability analyses as a measure of reliability. The idea is comparable to split-half reliability: We aggregated means for each participant separately over the odd half of the diary days (Days $1,3,5, \ldots$ to 153 ) and over the even half of the diary days (Days 78-154). Doing so resulted in two means for each participant and each construct. For each construct we then calculated the correlation between the mean of the odd half with the mean of the even half across all participants. The resulting stability scores ranged between .94 and .98 (see Table 1), which can be interpreted as very high.

\section{Data Analysis}

Multilevel analyses were calculated using the $\mathrm{R}$ package lme4 (Bates et al., 2015) with students on Level 2 and days within students on Level 1 . We tested for significance at the $5 \%$ level. As we were interested in possible differences regarding our hypothesized regression paths in the Lecture Period (Week 1 to Week 12) versus Non-Lecture Period (Week 13 to Week 22), we tested Hypothesis 1 with two models (dependent variable: daily study satisfaction in the lecture period vs. non-lecture period). As we were also interested in IM and EM, our approach led to 2 (lecture vs. non-lecture period) $\times 2$ (IM vs EM) different models for testing Hypotheses 2 and 3, respectively.

We tested each model by including (1) the trait variables from the initial survey as Level 2 predictors (controls), (2) the state variables of the present day (testing Hypothesis 1) or the previous day (testing Hypothesis 2) as Level 1 predictors, and (3) adding the respective autoregressive parameters of intrinsic or extrinsic academic motivation as random effects (testing Hypothesis 2).

Regarding Hypothesis 1, we tested the slopes for the relationship between the SRL components (i.e., planning, self-efficacy, time investment, effort, concentration, and procrastination) and study satisfaction (for the lecture pe- 


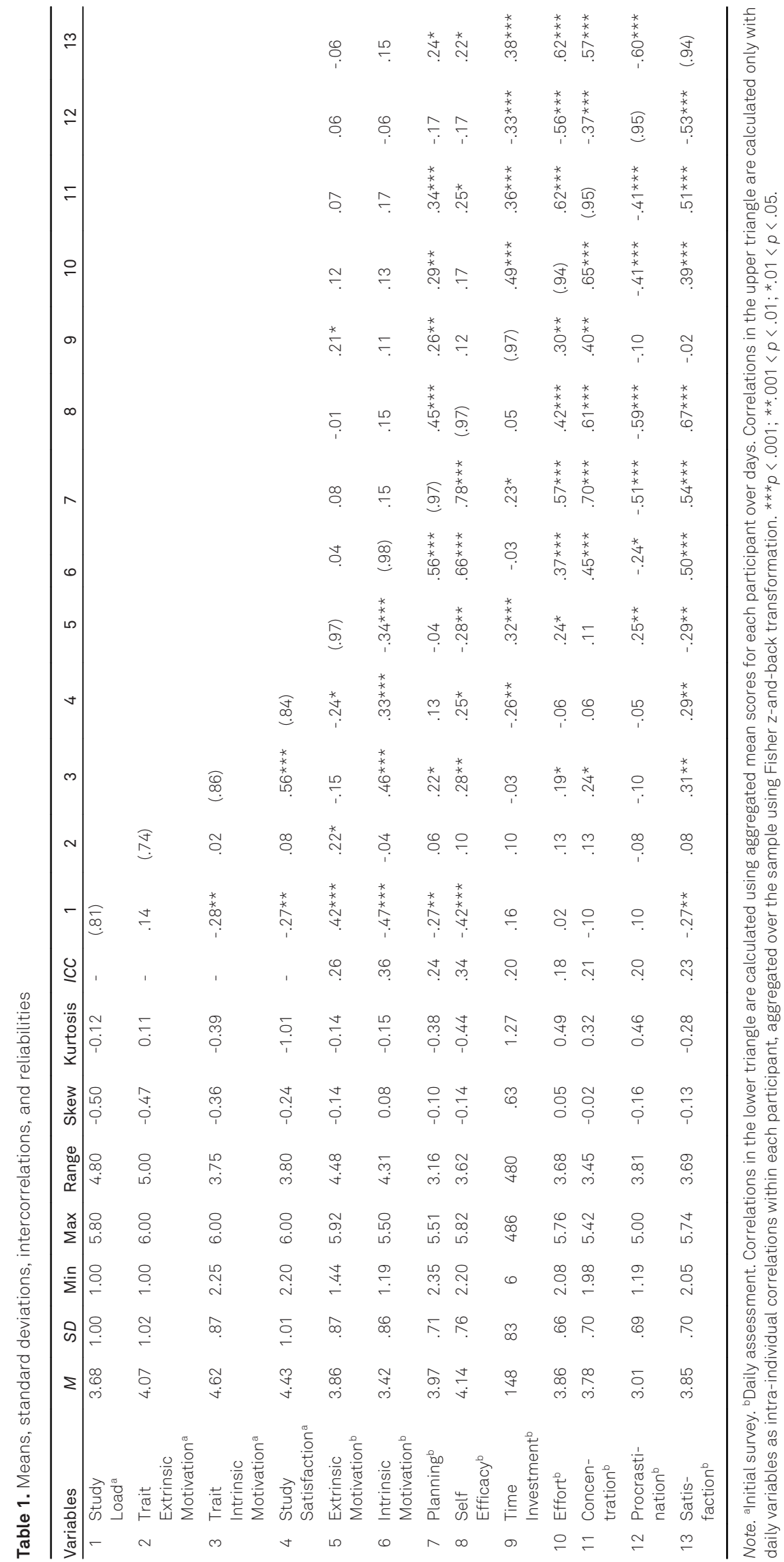


riod and the non-lecture period, respectively). For Hypothesis 2 , we tested the slopes between study satisfaction and IM/EM, while controlling for all other variables that were included in our models when testing Hypothesis 1 (again, for the lecture period and non-lecture period, respectively). In order to test our mediation hypotheses (Hypotheses 3 and 4), we used the estimates derived from the analyses regarding Hypothesis 1 (Path a: SRL components on study satisfaction), and the estimates derived from the analyses regarding Hypothesis 2 (Path $b$ : study satisfaction on IM/EM) as inputs for Selig and Preacher's (2008) Monte Carlo procedure to derive $95 \%$ confidence intervals (based on 20,000 resamples) for the indirect relationships between SRL predictors and IM/EM, through academic motivation.

We also tested whether SRL predictors of the previous day show direct effects on IM and EM (path $c^{\prime}$ ) beyond the proposed mediation effect through study satisfaction. These analyses were exploratory in nature.

\section{Results}

\section{Descriptive Results}

Table 1 provides an overview of the means, standard deviations, correlations, and reliabilities (in parentheses) for all variables used in our analyses. In order to calculate correlations of diary variables, we aggregated a mean score for each participant as proposed by Schmitz and Skinner (1993). These correlations are shown in the lower triangle of Table 1 . We also calculated intra-individual correlations for each participant, which we then aggregated over the entire sample using Fisher z-and-back transformation. These correlations are displayed in the upper triangle of Table 1.

For our dependent variables (IM and EM in both lecture and non-lecture period) and the mediator variable (study satisfaction in both lecture and non-lecture period), the intraclass correlations (ICC) were between .30 and .49 , indicating that a substantial part of the variance could be explained by different students (Level 2). Therefore, it is necessary to apply multilevel modeling to our data. The mediator variable (study satisfaction in both lecture and non-lecture period) did not yield high values for the ICC. However, in order to make a comparison with the other models easier, we also present these models with the same multilevel structure.

\section{Random Effects for Autoregressive Predictors}

In all four multilevel models described above, we included random effects only for the respective autoregressive predictor. For example, when IM was the dependent variable, we allowed individual slopes for IM on the previous day. A deviance test was conducted in order to compare the random effects model with the respective model with fixed slopes for all participants. As the deviance tests show, the random effect models were superior in all four cases, that is, for IM both in the lecture period, $\chi^{2}(2)=$ 88.23, $p<.001$, and in the non-lecture period, $\chi^{2}(2)=$ $114.14, p<.001$, as well as for EM both in the lecture period, $\chi^{2}(5)=289.74, p<.001$, and in the non-lecture period, $\left.\chi^{2}(5)=144.32, p<.001\right)$. We therefore included random effects for the respective autoregressive predictor in each of the models.

\section{Effects of SRL Components on Study Satisfaction}

In order to test Hypothesis 1, we regressed our mediator variable (study satisfaction) on the proposed predictor variables (SRL components: planning, self-efficacy, time investment, effort, concentration, and procrastination) while controlling for trait variables from the initial survey. Table 2 depicts the corresponding results, separately for the lecture period and the non-lecture period.

While planning (H1a) did not show the expected effect, we found significant effects for all other SRL components on study satisfaction in both the lecture period and the non-lecture period. Therefore, we found evidence for our hypotheses concerning self-efficacy ( $\mathrm{H} 1 \mathrm{~b} ; b=.07, p<.001$ and $b=.07, p<.001$, for the lecture and the non-lecture period, respectively), time investment (H1c; $b=.12, p<$ .001 and $b=.03, p=.02$ ), effort (H1d; $b=.24, p<.001$ and $b=.22, p<.001$ ), concentration (H1e; $b=.25, p<.001$ and $b=.27, p<.001$ ), and procrastination (H1 $\mathrm{f} ; b=-.28, p<$ .001 and $b=-.33, p<.001)$.

\section{Effects of Study Satisfaction on Motivation}

In order to test Hypothesis 2, we regressed our dependent variables (IM and $\mathrm{EM}$ ) on the proposed mediator variable (study satisfaction) while controlling for trait variables from the initial survey, autoregressive effects, and the proposed predictor variables (SRL components: planning, self-efficacy, time investment, effort, concentration, and procrastination). Table 3 depicts the corresponding resul- 
Table 2. Fixed effects estimates (top) and random effects estimates (bottom) for multilevel models of the predictors of students' daily study satisfaction

\begin{tabular}{|c|c|c|c|c|c|c|}
\hline \multirow[b]{3}{*}{ Predictors } & \multicolumn{6}{|c|}{ Study satisfaction } \\
\hline & \multicolumn{3}{|c|}{ Lecture period } & \multicolumn{3}{|c|}{ Non-lecture period } \\
\hline & Estimates & $\mathrm{Cl}$ & $t$ & Estimates & $\mathrm{Cl}$ & $t$ \\
\hline (Intercept) & $-0.06 * \star \star$ & $-0.08--0.04$ & -6.33 & $-0.08 * \star \star$ & $-0.12--0.03$ & -3.42 \\
\hline \multicolumn{7}{|l|}{ Initial Survey } \\
\hline Study Load & $-0.02 *$ & $-0.04--0.00$ & -2.17 & -0.03 & $-0.07-0.02$ & -1.23 \\
\hline Trait Extrinsic Motivation & 0.01 & $-0.01-0.03$ & 0.85 & 0.01 & $-0.04-0.05$ & 0.28 \\
\hline Trait Intrinsic Motivation & 0.01 & $-0.01-0.03$ & 0.78 & -0.00 & $-0.05-0.05$ & -0.12 \\
\hline Study Satisfaction & -0.02 & $-0.04-0.00$ & -1.62 & -0.04 & $-0.09-0.01$ & -1.46 \\
\hline \multicolumn{7}{|l|}{ Diary (Previous Day) } \\
\hline Extrinsic Motivation & $-0.04 * * \star$ & $-0.06--0.02$ & -3.71 & $-0.07 \star \star \star$ & $-0.11--0.04$ & -4.53 \\
\hline Intrinsic Motivation & 0.01 & $-0.02-0.03$ & 0.45 & 0.01 & $-0.02-0.04$ & 0.44 \\
\hline Planning & 0.01 & $-0.01-0.03$ & 0.76 & 0.01 & $-0.02-0.05$ & 0.87 \\
\hline Self-Efficacy & $0.07 * \star \star$ & $0.05-0.09$ & 6.35 & $0.07 * \star \star$ & $0.04-0.10$ & 4.13 \\
\hline Time Investment & $0.12 * \star \star$ & $0.10-0.14$ & 11.42 & 0.03 * & $0.01-0.06$ & 2.42 \\
\hline Effort & $0.24 * \star \star$ & $0.21-0.27$ & 16.92 & $0.22 * * *$ & $0.18-0.26$ & 10.69 \\
\hline Concentration & $0.25 * * *$ & $0.23-0.27$ & 20.79 & $0.27 * * *$ & $0.24-0.30$ & 16.26 \\
\hline Procrastination & $-0.28 * \star \star$ & $-0.31--0.26$ & -23.58 & $-0.33 * \star \star$ & $-0.37--0.30$ & -20.16 \\
\hline \multicolumn{7}{|l|}{ Random Effects } \\
\hline$\sigma^{2}$ & 0.51 & & & 0.50 & & \\
\hline$\tau_{00}$ & 0.00 student & & & 0.02 student & & \\
\hline ICC & 0.00 & & & 0.05 & & \\
\hline$N$ & $105_{\text {students }}$ & & & 88 students & & \\
\hline Observations & 6,157 & & & 3,501 & & \\
\hline Marginal $R^{2} /$ Conditional $R^{2}$ & $0.472 / 0.473$ & & & $0.483 / 0.507$ & & \\
\hline Deviance & $13,276.922$ & & & $7,598.568$ & & \\
\hline Log-likelihood & $-6,638.461$ & & & $-3,799.284$ & & \\
\hline
\end{tabular}

ts, separately for IM and EM as well as for the lecture period and the non-lecture period.

We found evidence for Hypothesis 2 in such a way that higher study satisfaction on one day predicts higher IM (H2a; $b=.10, p<.001$ and $b=.11, p<.001$, for the lecture and the non-lecture period, respectively) and lower EM (H2b; $b=-.12, p<.001$ and $b=-.10, p<.001)$ on the following day.

\section{Mediated Effects of SRL Components on Motivation Via Study Satisfaction}

In order to test Hypothesis 3, we estimated the indirect effects of our proposed predictor variables (SRL components: planning, self-efficacy, time investment, effort, concentration, and procrastination) on the dependent variable IM, mediated by study satisfaction. Conceptually, this corresponds to the multiplication of Path $a$ and Path $b$ in Figure 1. Table 4 depicts the corresponding results, separately for the lecture period and the non-lecture period.

While we found no indirect effect of planning on IM (H3a), all other SRL components showed the proposed indirect effects. We found evidence for our mediation hypotheses concerning self-efficacy ( $\mathrm{H} 3 \mathrm{~b} ; b=.0073$ and $b=$ .0075 , for the lecture and the non-lecture period, respectively), time investment (H3c; $b=.0127$ and $b=.0037$ ), effort (H3d; $b=.0160$ and $b=.0240$ ), concentration (H3e; $b=.0257$ and $b=.0300)$, and procrastination (H3f; $b=$ -.0292 and $b=-.0370)$.

Analogously, in order to test Hypothesis 4, we estimated the indirect effects of our proposed predictor variables (SRL components: planning, self-efficacy, time investment, effort, concentration, and procrastination) on the dependent variable EM, mediated by study satisfaction. Again, Table 4 depicts the corresponding results, separately for the lecture period and the non-lecture period.

While we found no indirect effect of planning on EM (H4a), all other SRL components showed the proposed 


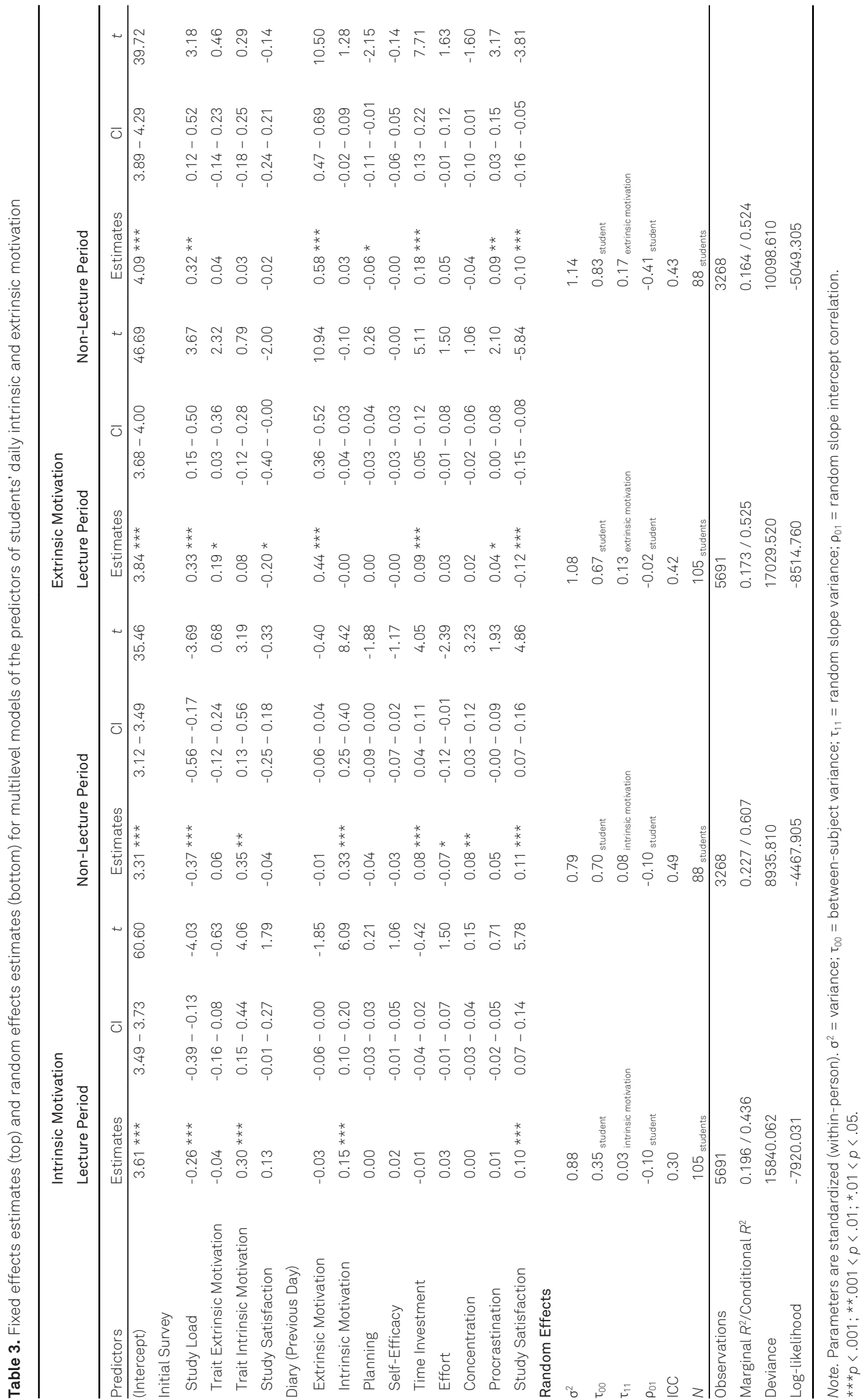


Table 4. Estimates for the indirect effect of self-regulated learning components on intrinsic and extrinsic motivation mediated by study satisfaction

\begin{tabular}{|c|c|c|c|c|c|c|c|c|}
\hline \multirow[b]{3}{*}{ Predictors } & \multicolumn{4}{|c|}{ Intrinsic Motivation } & \multicolumn{4}{|c|}{ Extrinsic Motivation } \\
\hline & \multicolumn{2}{|c|}{ Lecture Period } & \multicolumn{2}{|c|}{ Non-Lecture Period } & \multicolumn{2}{|c|}{ Lecture Period } & \multicolumn{2}{|c|}{ Non-Lecture Period } \\
\hline & Estimates & $\mathrm{Cl}$ & Estimates & $\mathrm{Cl}$ & Estimates & $\mathrm{Cl}$ & Estimates & $\mathrm{Cl}$ \\
\hline Planning & 0.0009 & $-0.0014-0.0033$ & 0.0016 & $-0.0021-0.0056$ & -0.0010 & $-0.0037-0.0015$ & -0.0015 & $-0.0056-0.0019$ \\
\hline Self-Efficacy & 0.0073 & $0.0042-0.0110$ & 0.0075 & $0.0033-0.0130$ & -0.0081 & $-0.0120--0.0047$ & -0.0070 & $-0.0130--0.0027$ \\
\hline Time Investment & 0.0127 & $0.0081-0.0180$ & 0.0037 & $0.0006-0.0074$ & -0.0141 & $-0.0200--0.0091$ & -0.0034 & $-0.0072--0.0006$ \\
\hline Effort & 0.0246 & $0.0160-0.0340$ & 0.0240 & $0.0140-0.0350$ & -0.0274 & $-0.0380--0.0180$ & -0.0226 & $-0.0350--0.0100$ \\
\hline Concentration & 0.0257 & $0.0170-0.0350$ & 0.0300 & $0.0180-0.0430$ & -0.0287 & $-0.0390--0.0190$ & -0.0282 & $-0.0440--0.0130$ \\
\hline Procrastination & -0.0292 & $-0.0400--0.0190$ & -0.0370 & $-0.0530--0.0220$ & 0.0326 & $0.0210-0.0440$ & 0.0349 & $0.0170-0.0540$ \\
\hline
\end{tabular}

Note. Parameters are standardized (within-person).

indirect effects. We found evidence for our mediation hypotheses concerning self-efficacy $(\mathrm{H} 4 \mathrm{~b} ; b=-.0081$ and $b$ $=-.0070$, for the lecture and the non-lecture period, respectively), time investment ( $\mathrm{H} 4 \mathrm{c} ; b=-.0141$ and $b=$ $-.0034)$, effort ( $\mathrm{H} 4 \mathrm{~d} ; b=-.0274$ and $b=-.0226)$, concentration (H4e; $b=-.0287$ and $b=-.0280)$, and procrastination (H4f; $b=.0326$ and $b=.0349$ ).

\section{Direct Effects of SRL Components on Motivation Beyond the Mediation Effect}

Exploratively, we also tested whether there were direct effects of our proposed predictor variables (SRL components: planning, self-efficacy, time investment, effort, concentration, and procrastination) on the dependent variables IM and EM beyond the mediation through study satisfaction. Simultaneously, we also tested whether the control variables from the initial survey were associated with our dependent variables, accompanied by tests for autoregressive effects for the dependent variables. Again, we refer to Table 3 for the corresponding results, separately for IM and EM as well as the lecture period and the non-lecture period.

\section{Intrinsic Motivation During Lecture Period}

After controlling for the mediation effect through satisfaction, daily IM during the lecture period was partly predictable by two trait variables from the initial survey. Study load was negatively associated with daily IM $(b=-.26$, $p<.001)$, meaning that lower study load contributed to higher daily IM. Further, trait IM was positively associated with state IM $(b=.30, p<.001)$. Trait EM and general study satisfaction did not contribute significantly to daily IM.

From all of the state variables assessed on the previous day, only two were found to have a significant effect on daily IM during the lecture period beyond the mediation effect: yesterday's IM (used as an autocorrelative predictor) contributed positively to today's IM $(b=.15, p<.001)$, which can be interpreted as a sign for some degree of dayto-day stability.

\section{Intrinsic Motivation During Non-lecture Period}

Generally speaking, the pattern of predictors for daily IM in the non-lecture period resembled the pattern in the lecture period, with slightly more pronounced findings. Trait IM positively predicted state IM with a weight similar to the one in the lecture period $(b=.35, p=.004)$. Study load showed an even higher impact on daily IM in the non-lecture period compared with the lecture period $(b=-.37, p<.001)$.

For the autoregressive part of the model, we found a higher impact in the non-lecture period $(b=.33, p<.001)$ than in the lecture period, meaning IM was more stable from day to day in the non-lecture period. Time investment $(b=.08, p<.001)$, effort $(b=-.07, p<.001)$, and concentration $(b=.08, p<.001)$ were found to have a direct effect on IM beyond the mediation effect.

\section{Extrinsic Motivation During the Lecture Period}

Among the control variables, three were positively related to state $\mathrm{EM}$ during the lecture period: trait $\mathrm{EM}(b=.19, p=$ $.02)$, general study satisfaction $(b=-.20, p=.02)$, and general study load ( $b=.33, p<.001)$. Trait IM, however, was not related to state EM.

We found a strong autoregressive effect of yesterday's EM on today' EM $(b=.44, p<.001)$, suggesting a rather high day-to-day stability of EM. From the predictor variables, yesterday's procrastination $(b=.04, p=.04)$ and time investment $(b=.09, p<.001)$ were positively associated with today's EM beyond the mediation effect.

\section{Extrinsic Motivation During the Non-lecture Period}

For the non-lecture period the pattern of predictors for daily EM changed slightly compared with the lecture pe- 
riod. From the control variables, only general study load was positively related to daily EM $(b=.32, p=.002)$.

The autoregressive effect of yesterday's EM was even stronger in the non-lecture period $(b=.58, p<.001)$. From the predictor variables, yesterday' planning $(b=-.06, p=$ $.01)$, procrastination $(b=.09, p<.001)$, and time investment $(b=.18, p<.001)$ were found to have an effect on EM beyond the mediation effect.

\section{Discussion}

The present study investigated daily fluctuations in IM and EM and their relation to SRL components in 105 university students who completed learning diaries over the course of an entire semester (5 months). Using multilevel modeling, we regressed academic motivation in the morning on SRL components measured on the previous day, with planning, self-efficacy, time investment, effort, concentration, and procrastination serving as predictor variables and study satisfaction as mediator variable. For all variables, a considerable amount of variance was attributed to Level 1 (days within students), emphasizing the necessity to investigate these constructs as processes using time series data.

The first hypothesis in our mediation analysis (see Figure 1, Path a) was that the mediator variable (study satisfaction) is related to the predictor variables (i.e., SRL components) on the same day. This hypothesis can be confirmed for self-efficacy, time investment, effort, concentration, and procrastination in the proposed direction. However, contrary to our hypothesis, planning was not associated with study satisfaction.

The second hypothesis (see Figure 1, Path $b$ ) assumed that the mediator variable (study satisfaction) on one day predicts the dependent variables on the following day, in the sense that higher study satisfaction is followed by higher IM and lower EM. This hypothesis was confirmed in our dataset both for IM and EM.

The third and fourth hypotheses (see Figure 1, Path $a^{*} b$ ) tested whether the effect of one day's predictor variables on next day's dependent variables was mediated by study satisfaction. As expected, the effects of self-efficacy, time investment, effort, concentration, and procrastination on IM were indeed mediated by study satisfaction. Analogously, the effects of self-efficacy, time investment, effort, concentration, and procrastination on EM were also mediated by study satisfaction. However, planning did not show a mediated effect, neither on IM nor on EM.

Taken together, these findings show strong support for the central idea of the process model of SRL (Schmitz \& Wiese, 2006): SRL components from both the preaction and the action phase combined contribute to the feeling of study satisfaction in the postaction phase, which in turn fosters a more desirable motivational state at the beginning of the next preaction phase (i. e., higher IM and lower EM; Ryan \& Deci, 2000). While there are several prior studies investigating the link between either two of the three phases of the process model (e.g., Caprara et al., 2008; Dermitzaki et al., 2009; Liborius et al., 2019; Pekrun et al., 2010; Wäschle et al., 2014), to the best of our knowledge we provide the first empirical evidence for a mediation linking all three phases together, thereby strengthening the iterative and cyclical nature of SRL.

\section{Differences Between Lecture Period and Non-lecture Period}

We investigated our mediation model separately for the lecture period and the non-lecture period, with remarkably similar results. Analyzing two different periods can be regarded as a test of replication. From this perspective, the mediation effects seem to be particularly robust. Notably, this also applies for the non-existing effect of planning, which could not be found in any of the periods.

On the other hand, we also exploratively investigated whether the predictor variables had a direct effect on the dependent variables that was not mediated by study satisfaction (see Figure 1, Path $c^{\prime}$ ). For these analyses we found several pronounced differences between the two periods of investigation. Depending on the time of sampling, different patterns of effects emerged, which makes a strong case for long-term investigations like the present study.

This finding could be attributed to the fact that students' daily experiences differ largely in these two periods: During lecture period, students' daily agenda is dominated by fixed appointments for classes, typically with a weekly frequency for each class, resulting in a different agenda for each day. While academic motivation for one's field of study should be relevant every day, motivation for a particular class might fluctuate on a daily basis. On the other hand, the non-lecture period is generally more characterized by tasks that last for several days or even weeks, for example, writing assignments, studying for exams, or internships. Thus, day-to-day fluctuations in academic motivation are less likely to occur in this period.

One might assume that another difference between the two periods could be that students generally had fewer tasks to do in the non-lecture period. While this certainly is true when it comes to attending classes, the amount of time spent for individual studying was almost the same in the lecture period and in the non-lecture period (for a comparison, see Liborius et al., 2019, Figure 3). 
However, students generally have more degrees of freedom in how they want to spend their days in the nonlecture period. In the absence of external regulation and structure, self-regulatory competency becomes more important, that is, students have to apply SRL strategies in order to create a structure for themselves (Theobald et al., 2018). This might explain why we found numerous direct effects of SRL components in the non-lecture period compared with relatively few direct effects in the lecture period.

\section{Separate Consideration of the SRL Components}

Planning was not related to study satisfaction but exhibited a direct effect on EM in the non-lecture period, with better planning on one day reducing EM on the following day. Although we did not formulate a hypothesis in this direction, from a theoretical perspective it is a plausible effect: Especially in situations with higher degrees of freedom (e.g., the non-lecture period), better planning on one day reduces the burden on the following day, whereas in situations with lower degrees of freedom (e.g., the lecture period), planning does not seem to have a systematic influence on EM. However, one might have expected a similar finding also for IM, which was not supported by our study.

Self-efficacy was not found to have a direct effect on either IM or EM beyond the mediation effect. In other words, the effect of self-efficacy on IM and EM was completely mediated though study satisfaction. Thus, in both the lecture period and the non-lecture period, higher selfefficacy in the morning contributed to higher study satisfaction in the evening, which in turn increased IM and decreased EM on the following day.

Time investment showed direct positive effects on EM in the lecture period and - even stronger in the non-lecture period - beyond the respective effect mediated by study satisfaction. In other words, time investment contributed to study satisfaction and thereby helped decrease EM on the following day, but simultaneously also directly increased EM. When it comes to the effect of time investment on IM, we found no direct effect beyond the mediated effect through study satisfaction in the lecture period, whereas in the non-lecture period an additional direct effect emerged beyond the mediated effect. These seemingly contradictory findings might reflect the ambiguous nature of time investment: While in some situations, increasing time investment might be an appropriate strategy - particularly when the time is used efficiently there are also situations in which increasing time investment leads to exhaustion and poorer quality. An impor- tant contribution to the empirical literature would be to differentiate which of these outcomes occurs in which situations.

Effort exhibited a negative direct effect on IM only in the non-lecture phase. This effect, however, worked in the opposite direction as the mediation effect. One explanation might be that effort only has a positive effect on IM when it is followed by study satisfaction - this would correspond to the mediation effect. Yet, effort without study satisfaction has a negative effect on IM. This only seems to be the case in the non-lecture period, which might be attributed to the fact that in the lecture period many tasks only last for one day - on the next day, a student may have a different class to attend that may be unrelated to today's motivation. For EM, on the other hand, we found a negative effect of effort completely mediated through satisfaction. This means that, as expected, putting effort into the learning process increases study satisfaction in both the lecture period and the non-lecture period, which in turn decreases EM on the following day.

Concentration was found to have a positive direct effect on IM in the non-lecture period beyond the mediated effect though study satisfaction. In other words, better concentration not only contributed to higher study satisfaction, which is beneficial for IM on the following day, it also had an additional beneficial effect in itself. On the other hand, no direct effects of concentration on EM were found.

Procrastination, lastly, showed a direct positive effect on EM in both the lecture and the non-lecture period beyond the mediation effect. This might be explained relatively easily: Procrastination not only has a malefic effect on the study satisfaction leading to an undesirable motivational state on the following day, it also directly increases the workload for the next day because the tasks accumulate. For IM, however, no such direct effect was found.

We found strong autoregressive effects for motivation, with EM being particularly stable from day to day. This might be interpreted as an overarching feeling of pressure that is prevailing every day. For IM this seems to be the case to a smaller degree, maybe because IM depends more on specific tasks that vary from day to day. For the autoregressive effects we also investigated random effects, which turned out to be significant. This means that individuals differ in the degree to which their motivational state on one day is influenced by their motivational state on the previous day. In other words, some individuals show higher variability in IM or EM from day to day than others. Interindividual differences in intraindividual variability (Wang et al., 2012) can be regarded as a trait that might be worth investigating in future studies. 


\section{Limitations}

The present study has to be interpreted in the light of several limitations. First of all, both SRL and motivation were measured using self-report instruments. While for motivation there might not be any plausible alternative than asking people themselves, many SRL researchers repeatedly questioned the validity of questionnaires for measuring metacognitive processes (Winne, 2010), proposing think-aloud protocols or digital trace data as alternatives. For our endeavor, however, both measures were not feasible because of either cost (students would not accept daily think-aloud tasks over 5 months without immense payments) or lack of availability (most studying still happens offline without leaving digital traces).

Further criticism concerns the diaries using one item per construct. We agree that it would be desirable to have at least three items per construct, reducing measurement error and allowing for the calculation of internal consistency as a more traditional aspect of reliability. However, this would have tripled the daily burden for participants, thereby increasing the risk of dropout, particularly given the long period of investigation in our study. Also, one-item scales in diary studies are well-established (e.g., Brose et al., 2012; Goetz et al., 2014).

Concerning our selection of constructs, many other sources of variance in IM and EM in the morning have not been measured in the present study. To name just a few, sleep (Wrzus et al., 2014), social conflicts (Volmer et al., 2012), and individual differences such as perfectionism (Harper et al., 2020) or cultural identification (Perunovic et al., 2011) have all been found to be influential for daily motivation, but could not be controlled in the present study.

Lastly, the number of participants $(N=105)$ may be regarded as small and insufficient to provide evidence for generalizations. However, as the focus of this study was on within-subject processes, one has to bear in mind that for each participant, up to 154 measurement points were used in the analyses, resulting in a total amount of 9,402 measurement points.

\section{Implications}

Although we certainly need more research in order to replicate our findings, there are several implications for theory and practice to be drawn from the present study. Concerning theory development, the process model of SRL (Schmitz \& Wiese, 2006) might need more specific assumptions. While it includes a plentitude of constructs that are well established predictors of successful learning, it lacks directed, quantified, and falsifiable predictions concerning the interplay between these constructs. Future studies should therefore investigate in more depth all possible combinations of SRL components to derive more precise predictions, including possible mediation effects. Concerning implications for practice, our findings might inform the development of interventions: Teaching students about the relationships between SRL components and motivation has been shown to help them to better regulate their motivation (e.g., Bellhäuser et al., 2016; Dörrenbächer \& Perels, 2016). Specifically, students could be trained to monitor their time investment, as we found a positive direct effect on IM (in the non-lecture period) but also an undesirable positive effect on EM (in both periods). Students should therefore choose wisely whether increasing their time investment is a good strategy in situations where they were dissatisfied with their own accomplishments the day before.

Beyond informing trainings, our findings could be useful in the context of online learning diaries: Implementing automatic individual feedback within the diary as a form of targeted micro-intervention could serve the purpose of detecting unfavorable motivational states and provide immediate advice for learners about feasible strategies in their situation. A comparable approach has been implemented by Wäschle, Lachner, et al. (2014), who integrated visual feedback in form of a dynamic line chart into a learning diary.

\section{Conclusion}

Longitudinal diary studies are in our view still the best method for providing ecologically valid data about students' daily SRL processes. Using diary data from 105 students, surveyed over an entire semester at university, we successfully demonstrated a central assumption of the process model of SRL (Schmitz \& Wiese, 2006): The effects of many SRL components from one day on academic motivation on the following day are at least partially mediated through study satisfaction. As our data further show, it is worthwhile investigating long periods such as an entire semester because relationships between SRL components can vary over time.

\section{References}

Abuhamdeh, S., \& Csikszentmihalyi, M. (2009). Intrinsic and extrinsic motivational orientations in the competitive context: An examination of person-situation interactions. Journal of Personality, 77(5), 1615-1635. https://doi.org/10.1111/j.14676494.2009.00594.x 
Bates, D., Mächler, M., Bolker, B., \& Walker, S. (2015). Fitting linear mixed-effects models using Ime4. Journal of Statistical Software, 67(1). https://doi.org/10.18637/jss.v067.i01

Baumert, J., Blum, W., Brunner, M., Dubberke, T., Jordan, A., Klusmann, U., Krauss, S., Kunter, M., Löwen, K., \& Neubrand, M. (2009). Professionswissen von Lehrkräften, kognitiv aktivierender Mathematikunterricht und die Entwicklung von mathematischer Kompetenz (COACTIV): Dokumentation der Erhebungsinstrumente [Teachers' professional knowledge, cognitively activating mathematics instruction, and the development of mathematical competence (COACTIV): Documentation of survey instruments]. Max-Planck-Institut für Bildungsforschung.

Bellhäuser, H., Lösch, T., Winter, C., \& Schmitz, B. (2016). Applying a web-based training to foster self-regulated learning - effects of an intervention for large numbers of participants. The Internet and Higher Education, 31, 87 -100. https://doi.org/10.1016/ j.iheduc.2016.07.002

Brose, A., Schmiedek, F., Lövdén, M., \& Lindenberger, U. (2012). Daily variability in working memory is coupled with negative affect: The role of attention and motivation. Emotion, 12(3), $605-$ 617. https://doi.org/10.1037/a0024436

Caprara, G. V., Fida, R., Vecchione, M., Del Bove, G., Vecchio, G. M., Barbaranelli, C., \& Bandura, A. (2008). Longitudinal analysis of the role of perceived self-efficacy for self-regulated learning in academic continuance and achievement. Journal of Educational Psychology, 100(3), 525-534. https://doi.org/10.1037/ 0022-0663.100.3.525

Deci, E. L., \& Ryan, R. M. (2012). Self-determination theory. In In P. A. M. Van Lange, A. W. Kruglanski, \& E. T. Higgins (Eds.), Handbook of theories of social psychology: Volume 1 (pp. 416-437). SAGE Publications. https://doi.org/10.4135/9781446249215. n21

Dermitzaki, I., Leondari, A., \& Goudas, M. (2009). Relations between young students' strategic behaviours, domain-specific self-concept, and performance in a problem-solving situation. Learning and Instruction, 19(2), 144-157. https://doi.org/10. 1016/j.learninstruc.2008.03.002

Dörrenbächer, L., \& Perels, F. (2016). More is more? Evaluation of interventions to foster self-regulated learning in college. International Journal of Educational Research, 78, 50-65. https:// doi.org/10.1016/j.ijer.2016.05.010

Eccles, J. S., \& Wigfield, A. (2002). Motivational beliefs, values, and goals. Annual Review of Psychology, 53, 109-132.

Goetz, T., Frenzel, A. C., Hall, N. C., Nett, U. E., Pekrun, R., \& Lipnevich, A. A. (2014). Types of boredom: An experience sampling approach. Motivation and Emotion, 38(3), 401 - 419. https://doi. org/10.1007/s11031-013-9385-y

Harper, K. L., Eddington, K. M., Lunsford, J., \& Hoet, A. C. (2020). Perfectionism and the impact of intrinsic and extrinsic motivation in daily life. Journal of Individual Differences, 41(3), $117-$ 123. https://doi.org/10.1027/1614-0001/a000310

Hidi, S. E., \& Renninger, K. A. (2019). Interest development and its relation to curiosity: Needed neuroscientific research. Educational Psychology Review, 31(4), 833 -852. https://doi.org/10. 1007/s10648-019-09491-3

Hiemstra, D., \& Van Yperen, N. W. (2015). The effects of strengthbased versus deficit-based self-regulated learning strategies on students' effort intentions. Motivation and Emotion, 39(5), 656 - 668. https://doi.org/10.1007/s11031-015-9488-8

Honicke, T., \& Broadbent, J. (2016). The influence of academic self-efficacy on academic performance: A systematic review. Educational Research Review, 17, 63-84. https://doi.org/10. 1016/j.edurev.2015.11.002

Isen, A. M., \& Reeve, J. (2005). The influence of positive affect on intrinsic and extrinsic motivation: Facilitating enjoyment of play, responsible work behavior, and self-control. Motivation and Emotion, 29(4), 295 - 323. https://doi.org/10.1007/s11031006-9019-8

Ketonen, E. E., Dietrich, J., Moeller, J., Salmela-Aro, K., \& Lonka, K. (2018). The role of daily autonomous and controlled educational goals in students' academic emotion states: An experience sampling method approach. Learning and Instruction, 53, 10 - 20. https://doi.org/10.1016/j.learninstruc.2017.07.003

Klassen, R. M., Krawchuk, L. L., \& Rajani, S. (2008). Academic procrastination of undergraduates: Low self-efficacy to selfregulate predicts higher levels of procrastination. Contemporary Educational Psychology, 33(4), 915-931. https://doi.org/10. 1016/j.cedpsych.2007.07.001

LePine, J. A., LePine, M. A., \& Jackson, C. L. (2004). Challenge and hindrance stress: Relationships with exhaustion, motivation to learn, and learning performance. Journal of Applied Psychology, 89(5), 883-891. https://doi.org/10.1037/0021-9010.89.5.883

Liborius, P., Bellhäuser, H., \& Schmitz, B. (2019). What makes a good study day? An intraindividual study on university students' time investment by means of time-series analyses. Learning and Instruction, 60(1), 310-321. https://doi.org/10.1016/j. learninstruc.2017.10.006

Locke, E. A., \& Schattke, K. (2019). Intrinsic and extrinsic motivation: Time for expansion and clarification. Motivation Science, 5(4), 277 - 290. https://doi.org/10.1037/mot0000116

Mouratidis, A., Michou, A., \& Vassiou, A. (2017). Adolescents' autonomous functioning and implicit theories of ability as predictors of their school achievement and week-to-week study regulation and well-being. Contemporary Educational Psychology, 48, 56 - 66. https://doi.org/10.1016/j.cedpsych.2016.09.001

Murayama, K., Goetz, T., Malmberg, L.-E., Pekrun, R., Tanaka, A., \& Martin, A.-J. (2017). Within-person analysis in educational psychology: Importance and illustrations. In D. W. Putwain \& K. Smart (Eds.), British Journal of Educational Psychology Monograph Series II: Psychological Aspects of Education - Current Trends: The Role of Competence Beliefs in Teaching and Learning (pp. $71-87$ ). Wiley.

Nowell, C. (2017). The influence of motivational orientation on the satisfaction of university students. Teaching in Higher Education, 22(7), 855-866. https://doi.org/10.1080/13562517.2017. 1319811

Patall, E. A., Steingut, R. R., Vasquez, A. C., Trimble, S. S., Pituch, K. A., \& Freeman, J. L. (2018). Daily autonomy supporting or thwarting and students' motivation and engagement in the high school science classroom. Journal of Educational Psychology, 110(2), 269 - 288. https://doi.org/10.1037/edu0000214

Pekrun, R., Goetz, T., Daniels, L. M., Stupnisky, R. H., \& Perry, R. P. (2010). Boredom in achievement settings: Exploring controlvalue antecedents and performance outcomes of a neglected emotion. Journal of Educational Psychology, 102(3), 531-549. https://doi.org/10.1037/a0019243

Perels, F., Gürtler, T., \& Schmitz, B. (2005). Training of self-regulatory and problem-solving competence. Learning and Instruction, 15(2), 123-139. https://doi.org/10.1016/j.learninstruc. 2005.04.010

Perunovic, W. Q. E., Heller, D., Ross, M., \& Komar, S. (2011). The within-person dynamics of intrinsic and extrinsic motivation, affective states, and cultural identification. Social Psychological and Personality Science, 2(6), 635-641. https://doi.org/10. $1177 / 1948550611405071$

Pintrich, P. (2000). The role of goal orientation in self-regulated learning. In B. J. Zimmerman \& D. H. Schunk (Eds.), Handbook of self-regulation of learning and performance (pp. 451-502). Taylor \& Francis. http://doi.apa.org/psycinfo/2001-01625-013

Radel, R., Pelletier, L., Baxter, D., Fournier, M., \& Sarrazin, P. (2014). The paradoxical effect of controlling context on intrinsic 
motivation in another activity. Learning and Instruction, 29, 95 102. https://doi.org/10.1016/j.learninstruc.2013.09.004

Reeve, J. (1989). The interest-enjoyment distinction in intrinsic motivation. Motivation and Emotion, 13(2), 83 - 103. https://doi. org/10.1007/BF00992956

Richardson, M., Abraham, C., \& Bond, R. (2012). Psychological correlates of university students' academic performance: A systematic review and meta-analysis. Psychological Bulletin, 138(2), 353 - 387. https://doi.org/10.1037/a0026838

Rosário, P., Núñez, J. C., Valle, A., González-Pienda, J., \& Lourenço, A. (2013). Grade level, study time, and grade retention and their effects on motivation, self-regulated learning strategies, and mathematics achievement: a structural equation model. European Journal of Psychology of Education, 28(4), 1311-1331. https://doi.org/10.1007/s10212-012-0167-9

Ryan, R. M., \& Connell, J. P. (1989). Perceived locus of causality and internalization: Examining reasons for acting in two domains. Journal of Personality and Social Psychology, 57(5), $749-$ 761.

Ryan, R. M., \& Deci, E. L. (2000). Intrinsic and extrinsic motivations: Classic definitions and new directions. Contemporary Educational Psychology, 25(1), 54-67. https://doi.org/10.1006/ceps. 1999.1020

Sansone, C., \& Harackiewicz, J. M. (2000). Intrinsic and extrinsic motivation: The search for optimal motivation and performance. Academic Press.

Scherrer, V., \& Preckel, F. (2019). Development of motivational variables and self-esteem during the school career: A meta-analysis of longitudinal studies. Review of Educational Research, 89(2), 211 -258. https://doi.org/10.3102/0034654318819127

Schmitz, B. (2006). Advantages of studying processes in educational research. Learning and Instruction, 16(5), 433-449. https://doi.org/10.1016/j.learninstruc.2006.09.004

Schmitz, B., \& Skinner, E. (1993). Perceived control, effort, and academic performance: Interindividual, intraindividual, and multivariate time-series analyses. Journal of Personality and Social Psychology, 64(6), 1010 -1028. https://doi.org/10.1037/ 0022-3514.64.6.1010

Schmitz, B., \& Wiese, B. (2006). New perspectives for the evaluation of training sessions in self-regulated learning: Time-series analyses of diary data. Contemporary Educational Psychology, 31(1), 64 - 96. https://doi.org/10.1016/j.cedpsych.2005.02.002

Selig, J. P., \& Preacher, K. J. (2008). Monte Carlo method for assessing mediation: An interactive tool for creating confidence intervals for indirect effects [Computer software]. Available from http://quantpsy.org/

Steinmayr, R., \& Spinath, B. (2007). Predicting school achievement from motivation and personality. Zeitschrift Für Pädagogische Psychologie, 21, 207 -216. https://doi.org/10.1024/1010-0652. 21.3.207

Taylor, G., Jungert, T., Mageau, G. A., Schattke, K., Dedic, H., Rosenfield, S., \& Koestner, R. (2014). A self-determination theory approach to predicting school achievement over time: the unique role of intrinsic motivation. Contemporary Educational Psychology, 39(4), 342-358. https://doi.org/10.1016/j.ced psych.2014.08.002

Theobald, M., Bellhäuser, H., \& Imhof, M. (2018). Identifying individual differences using log-file analysis: Distributed learning as mediator between conscientiousness and exam grades. Learning and Individual Differences, 65, 112-122. https://doi. org/10.1016/j.lindif.2018.05.019

Trautwein, U. (2007). The homework-achievement relation reconsidered: Differentiating homework time, homework frequency, and homework effort. Learning and Instruction, 17(3), 372-388. https://doi.org/10.1016/j.learninstruc.2007.02.009

Volmer, J., Niessen, C., Binnewies, C., \& Sonnentag, S. (2012). Do social conflicts with customers at work encroach upon our private lives? A diary study. Journal of Occupational Health Psychology, 17(3), 304 -315. https://doi.org/10.1037/a0028454

Wang, L. P., Hamaker, E., \& Bergeman, C. S. (2012). Investigating inter-individual differences in short-term intra-individual variability. Psychological Methods, 17(4), 567-581. https://doi. org/10.1037/a0029317

Wäschle, K., Allgaier, A., Lachner, A., Fink, S., \& Nückles, M. (2014). Procrastination and self-efficacy: Tracing vicious and virtuous circles in self-regulated learning. Learning and Instruction, 29, 103 -114. https://doi.org/10.1016/j.learninstruc.2013.09.005

Wäschle, K., Lachner, A., Stucke, B., Rey, S., Frömmel, C., \& Nückles, M. (2014). Effects of visual feedback on medical students' procrastination within web-based planning and reflection protocols. Computers in Human Behavior, 41, 120-136. https://doi.org/10.1016/j.chb.2014.09.022

Watson, D. (1988). Intraindividual and interindividual analyses of positive and negative affect: Their relation to health complaints, perceived stress, and daily activities. Journal of Personality and Social Psychology, 54(6), 1020 -1030. https://doi.org/10.1037/ 0022-3514.54.6.1020

Winne, P. H. (2010). Improving measurements of self-regulated learning. Educational Psychologist, 45(4), 267 - 276. https://doi. org/10.1080/00461520.2010.517150

Wrzus, C., Wagner, G. G., \& Riediger, M. (2014). Feeling good when sleeping in? Day-to-day associations between sleep duration and affective well-being differ from youth to old age. Emotion, 14(3), 624-628. https://doi.org/10.1037/a0035349

Zimmerman, B. J. (2000). Attaining self-regulation: A social cognitive perspective. In M. Boekaerts, M. Zeidner, \& P. R. Pintrich (Eds.), Handbook of self-regulation (pp. 13-39). Elsevier Academic Press. http://doi.apa.org/psycinfo/2001-01625-001

\section{Funding}

Open access publication enabled by Johannes GutenbergUniversity Mainz

\section{ORCID}

Henrik Bellhäuser

(iDhttps://orcid.org/0000-0003-4414-7795

\section{Henrik Bellhäuser}

Johannes Gutenberg-University Mainz

Binger Str. 14-16

55122 Mainz

Germany

bellhaeuser@uni-mainz.de 